Open Access

\title{
Research ethics education in Korea for overcoming culture and value system differences
}

\author{
Hwan-Jin Nho
}

\author{
Correspondence: hjnho@dgist.ac.kr \\ Daegu Gyeongbuk Institute of \\ Science and Technology(DGIST), \\ 333, Techno Jungang-Daero, \\ Hyeonpung-Myeon, Dalseong-Gun, \\ Daegu 711-873, Korea
}

\begin{abstract}
Although ethical standards and procedures for research in Korea have developed closer to global standards, applying those standards and procedures have led significant conflicts widely due to the cultural differences. In Korea where relationship-centered East Asian values are crucial, it is difficult for 'internal whistleblowing' and 'conflicts of interest management' to function properly. At universities, it is difficult to form an equal relationship to have a free discussion between professors and students. Also, the research community has been influenced by side effects such as 'respect for quantity and speed', 'excessive competition', and 'mammonism' that have permeated Korean society during its modernization process. Students have taken such values for granted, too. These circumstances disable research ethics system to function properly and have negative influence on organization development by discouraging open innovation. In this context, how can we educate students to follow the global standards as well as dealing with conflicts derived from cultural differences wisely? I propose that the overarching principle of research ethics education should not be a 'delivery of knowledge' but be a 'change in the way of thinking'. In this paper, five-stage education is proposed. As education methods, discussing of dilemma cases, avoiding remote online education and leading the whole team teaching classes by one head lecturer are recommended. In addition, classroom education should be provided together with social education to change the students' ways of thinking.

As for social education, self-effort of universities and operational behaviour of research laboratories are two most important aspects. The government should establish legislation and expand financial support to facilitate these changes. It is very important that the universities should become key drivers that purify their member societies so that the nation may prosper.
\end{abstract}

Keyword: Research ethics, Research ethics education, Scope of research ethics, Disparity in Korean society, Educational method

\section{Springer}

(c) 2016 Nho. Open Access This article is distributed under the terms of the Creative Commons Attribution 4.0 International License (http://creativecommons.org/licenses/by/4.0/), which permits unrestricted use, distribution, and reproduction in any medium, provided you give appropriate credit to the original author(s) and the source, provide a link to the Creative Commons license, and indicate if changes were made. 


\section{Introduction}

In most cases, research ethics educators in Korea teach graduate students Western (or American) ethical norms for research as the global standards. In most of their courses, rather than injecting ethical knowledge into students, they emphasize understanding ethical concepts and institutional principles for application in the real world. For this purpose, the backgrounds of established ethical norms as well as the current institutional standards and procedures are explained, and ethical dilemma situations are discussed. In this process, however, educators come to face the practical limitations in Korean society. There is a disparity between the values research ethics education pursues and those the society really respects. For instance, though educators explain students about the consequential hazards of neglecting 'conflicts of interest' while conducting researches, the 'real' society neglects the need for managing such conflicts of interest. Sometimes, we are afraid that some students, who have learned 'internal whistle-blowing' concepts really become whistle-blowers, but only to repent for being disadvantaged. The cause of disparity seems to lie in the cultural and value system differences.

Korea has achieved a great financial success thanks to the speedy economic development. Korean society, however, is evaluated yet to be immature in mental aspects. During its modernization process, the greatest virtues of Korean society were fast achievement and quantitative growth. This value system seemed to lead the backsliding of the overall ethical level in the society. Ethical drawbacks, which are often found in Korean society, are as follows:

- Ignoring procedural ethics to obtain quick results;

- Ignoring qualitative process to obtain superior quantitative outcomes;

- Camouflaging inner conflicts valuing more outer appearance;

- High possibility of ethical flaws in upstarts in general;

- Society often goes as far as to consider norm-followers as 'idiots'.

This paper identifies research ethics problems derived from the unique situation of Korean society and their causes, and then proposes education methods to overcome those problems as naturally as possible.

\section{Whole scope of research ethics}

There is no universal agreement among scholars on the scope of research ethics. The classification of the research ethics scope may vary among scholars. In this paper, it is proposed to set the whole scope of research ethics as shown in the below table. In the table, research ethics is classified into three types according to the background of the formation of ethics: Bio-ethics, RCR (Responsible Conduct of Research), and academic ethics. They are buttressed by a total of 13 norms. It is recommended to study the philosophical backgrounds of research ethics including the general introduction.

Scope and Classification of Research Ethics 


\begin{tabular}{|c|c|c|}
\hline Classification & Ethical Norm & Major Concepts \\
\hline General & What is research ethics? & Ethics, Scientific Research, Value Orientation, Ethical Dilemma \\
\hline \multirow[t]{3}{*}{ Bio-Ethics } & $\begin{array}{l}\text { Research ethics on human } \\
\text { subjects }\end{array}$ & $\begin{array}{l}\text { Research on Human Subjects, Protection of Human Subjects, } \\
\text { Informed Consent, IRB }\end{array}$ \\
\hline & $\begin{array}{l}\text { Research ethics on embryos } \\
\text { and human materials }\end{array}$ & $\begin{array}{l}\text { Human Genes, Human Embryos, Protection of Private } \\
\text { Information, IRB }\end{array}$ \\
\hline & $\begin{array}{l}\text { Research ethics on animal } \\
\text { experiments }\end{array}$ & Animal Welfare, 3Rs, IACUC, Federal-wide Assurance \\
\hline \multirow[t]{6}{*}{$\mathrm{RCR}$} & Research misconduct & $\begin{array}{l}\text { Fabrication, Falsification, Plagiarism, Inquiry, Investigation } \\
\text { procedures, Retaliation, Interference }\end{array}$ \\
\hline & $\begin{array}{l}\text { Management of research data } \\
\text { and laboratory notes }\end{array}$ & $\begin{array}{l}\text { Institutional Ownership Principle, Disclosure Principle, Researcher } \\
\text { Responsibility }\end{array}$ \\
\hline & Publication ethics & Authorship, Copyright, Article Review Ethics \\
\hline & $\begin{array}{l}\text { Norm on joint research } \\
\text { (Research contract) }\end{array}$ & Kick-off Meeting, Allocation of Assignments, Share of Results \\
\hline & $\begin{array}{l}\text { Technology management } \\
\text { norm }\end{array}$ & $\begin{array}{l}\text { Disclosure of Technology, Patent Right, Technology Transfer, } \\
\text { Material Transfer }\end{array}$ \\
\hline & $\begin{array}{l}\text { Management of conflicts of } \\
\text { interest }\end{array}$ & $\begin{array}{l}\text { Disclosure of Interest, Management, Avoidance, Startup by } \\
\text { professors }\end{array}$ \\
\hline \multirow{4}{*}{$\begin{array}{l}\text { Academic } \\
\text { practice }\end{array}$} & Professorial ethics & Peer Review, Self-Proving Validity, Professor's Responsibility \\
\hline & Student ethics & Learning Ethics, School Ethics, Honor Code, Student Trial \\
\hline & Norm on mentoring & Student Guidance, Thesis Advice, Skill-building Guidance \\
\hline & $\begin{array}{l}\text { Academic freedom and social } \\
\text { responsibility }\end{array}$ & $\begin{array}{l}\text { History of Universities, Spirit of University, Social Role of } \\
\text { University, Autonomy of University, Social Activities of Professors }\end{array}$ \\
\hline
\end{tabular}

'Bioethics' is a most recently established ethical system concept. The concept of the protection of human subjects has been embodied in the Nuremberg Code (1947), the Declaration of Helsinki (1964), and the Belmont Report (1979). Later, the rapidly developing Biology gave birth to an ethical concept on the use of human embryos after the 2000s. The concept of laboratory animal welfare began to form thanks to the efforts of animal protection organizations during the middle of the 1900s. Now, strict ethical norms on laboratory animal welfare are set in place.

'Responsible Conduct of Research (RCR)' became an institutional concept in 2000 after certain large-scale research misconduct cases, mostly in the USA, during the 1980s. In Korea, norm-setting for RCR began with the establishment of the 'Guidelines on Ensuring Research Ethics' in 2007. Many aspects of RCR, however, have not yet been dealt with officially. It seems that this has not taken root in Korean society.

'Academic Practice' is the oldest norm. With the beginning of European higher education during the Middle Ages, the powers and responsibilities of professors had gradually taken form. The institution of higher education transferred to the USA, combined with liberalism and began to establish academic freedom, professorial ethics, and social responsibility of professors during the mid-1900s.

\section{Research ethics and open innovation}

Nowadays, open innovation concept is more and more adopted in various areas such as business administration, public policy, local science and technology policy, and so on. Moreover, open innovation is regarded as a crucial methodology for the growth of 
organizations such as universities and public research institutes as well as companies. Open innovation explains why knowledge sharing and cooperative work between inand out- bound of organizations are important. In this paragraph, the relationship between research ethics and open innovation would be explained.

Intuitively, it is easy to think that research ethics is connected with the knowledge generation, and separately, open innovation is connected with the knowledge exchange. However, research ethics influence not only $R \& D$ employees' attitude but also $R \& D$ management system such as research data, technology transfer, and research contract. In other words, research ethics influence a lot of R\&D employees' activities such as knowledge generation, knowledge sharing, and knowledge exchange. Therefore, research ethics is closely related to the open innovation. Some literatures support this argument.

The social effect of research ethics can be explained as follows (Resnik 2010). Research ethics;

- promotes the research purpose such as expansion of knowledge and avoidance of error.

- promotes the essential values for collaborative work, such as trust, accountability, mutual respect, and fairness.

- helps to guarantee that researchers can be held accountable to the public.

- helps to build public support for research.

- promotes to spread a variety of other important moral and social values such as social responsibility, human rights, animal welfare, compliance with the law, and health and safety.

Thus, research ethics can shape the public perception on researchers, and the public gives trust and respect to the researchers in return. Then, confidence in research facilitates communication between in- and out- bound of organizations and promotes cooperation and knowledge exchange. Some studies on individual level in open innovation point out that:

- The success of knowledge exchange heavily depends on employees' knowledge exchange efforts (Husted \& Michailova 2010).

- Intrinsic motivational factors are more positively influential rather than extrinsic motivational factors toward knowledge sharing attitudes in case studies of Korean companies (Jeon et al. 2011).

- The degree of technology transfer varies enormously in different geographical locations. In technology transfer activities, US firms are more active than European firms while Asian firms are very passive (Hossain 2013).

- Among motivational factors such as attitude, subjective norm, and perceived behavioral control on employees' intention to exchange their knowledge, subjective norm has the strongest impact on it though attitude and perceived behavioral control also shows highly significant and positive effects in case studies of R\&D departments of German companies (Verena \& Cornelius 2014).

Thus, knowledge management is strongly influenced by the cultural and human factors as well as organizational strategy and structure (Van de Vrande et al. 2009). These factors are also relevant to research ethics. Therefore, research ethics is 
heavily associated with open innovation through knowledge management; research ethics and open innovation play important roles for the organization's growth in diverse dimensions. If we think more deeply, research ethics forms the basis for organizational development and creates an environment to make open innovation possible.

\section{Unique research ethical problems in Korean society} Disparity caused by East Asian thinking

'East Asian thinking' refers to a system of thinking, which exists uniquely in China, Korea, and Japan all of which have been influenced by Taoism, Confucianism, and Buddhism. Its characteristics are thinking collectively, interdependently, and comprehensively. On the contrary, Western people tend to think individualistically, independently, and analytically (Nisbett 2003). The Western culture has valued the autonomy of individuals while the East Asian culture has respected harmonious human relationship. Unlike Western society, East Asian society tends to value the honor of groups rather than the honor of individuals. In East Asian societies, all members of a group feel ashamed when a member of the group commits a misconduct. It seems that these differences between East Asian thinking system and that of Western's are also reflected in research ethics. Thus, it is difficult for East Asian society to accept some parts of research ethics which have been systemized by the Western culture. Disparities in thinking are frequently found in the areas below:

- Management of conflicts of interest

- Internal whistle-blowing

- Joint research activities

- Report of misconduct to the government

\section{Disparity due to 'Top-down democracy'}

It seems that democracy, which began as a form of government during the period of ancient Greece, went through social democracy and had finally settled deep in Western society as a way of life. In Western society, principles of democracy such as respect for humans, freedom, and equality seem to be applied to private contracts between individuals as well as to the operational modes of entities or groups and reflected relatively well on the ethical system. The concepts of equality and respect for human are permeated, for example, in the written agreement of the human subject, employment contracts of researchers, principles of peer review, mentoring manuals, and arrangements for the investigation of research misconduct.

After the liberation of Korea, politicians and intellectuals took the lead in introducing democracy. Korean democracy is, therefore, short in history and may be said to be top-down. At that time, the general public elected the President of the nation without properly understanding the concept of democracy remaining thinking in an East Asian way, in other words, thinking collectively, hierarchically, pursuing wealth and honor, in their lives. It can be said that the principles of democracy, even at present, are not fully established in society. Even researchers of science and technology are not, in most cases, familiar with the principles of democracy, which often leaves 'top dogs' including government officials, heads of 
institutions, guiding professors, superiors, and seniors to abuse their power. As the result, the following ethical problems in research often take place:

- Non-democratic operation of universities and research institutes (leader-centric decision making, neglecting union voices, etc.)

- Non-democratic decision making process inside the labs (due to professor-seniorcentered hierarchy)

- Undocumented student rights (due to dominant discretion of the guiding professor)

- Undocumented researcher rights (only in appointment letters without employment contracts)

- Passive participation of researchers in the process of important decision-making

- Factionalism and its unfair leverage (unreasonable protection of the profit of factional minorities)

- Practice of avoiding specifications in research contract (many statements are subject to interpretation by the superior)

\section{Disparity due to rapid economic development}

Korea has achieved unparalleled economic growth very rapidly. In these days, a symptom, regarded as the growth limits of capitalism, has appeared in Korea (Yun 2015). Korean War tore the country down to ruins and put the people in extreme poverty. After the armistice of the fratricidal war in 1953, Korea also suffered from widespread political turmoils. It was not until the establishment of the military regime in 1961 to carry out elaborate plans for political stabilization and economic development. At that time, economic development was the overarching value and on top of the priorities based on the national development model that depended heavily on science and technology (Kim 1997). It is evaluated that the current growth and achievements of Korea owe very much to the well-organized planning and intensive efforts.

During the national development period, Korea imitated Western-style research institutes, researcher management, and project management in appearance; however, it didn't fully take after scientific management principles and ethical principles. This has caused many adverse side effects. 'Quantity- and speed-centric evaluation,' 'excessive competition', 'mammonism', and 'government-lead decision making' are widespread across the nation including the research community. At least, partly for this reason, society does not evaluate the reliability of the science community highly (Lee 2013). Frequent issues of the science community are as follows:

- Researchers often make more efforts to secure 'research funding' than to conduct 'research'. (The title of the research plan is exaggerated.)

- Researchers are indifferent to the level of quality as their products are evaluated quantitatively. They stick to the number of papers. (Research is deteriorated into the paper production rather than contributing to academic development.)

- As speed is a virtue, ethical reviews are considered to be burdensome. (IRB and IACUC are thought to be annoying.)

- Business startups are encouraged in spite of deficient technology management system (Disclosure and evaluation of technology). This often leads to the conflicts of interest. (Policy failures often take place.) 
- Self-evolving arrangements, based on autonomy, do not exist. (The government always takes the lead.)

\section{Other important ethical problems}

Korea does not have experience in making an academic discipline in science fields by itself and developing its systematic structure independently. Most Korean scientists have studied in Western society (mostly in the USA or Europe). Regrettably, development of 'science' does not seem to contribute substantially to the development of 'engineering'. Rather, engineering scholars who studied in Western society develop 'engineering'. Engineering, however, does not seem to contribute to 'resolving the social problems'. The government directly resolves important social problems through resourceful experts of Western society. Consequently, 'science,' 'technology', and 'resolving social problems' are not interconnected but broken off. Under these circumstances, many worrisome problems take place in terms of research ethics as convergence research is emphasized:

- In a joint research, contractual practice does not clearly define shared provision of resources, role division, and distribution of achievement. In addition, insufficient arrangements for the resolution of conflicts of interest often cause new conflicts of interest.

- To avoid conflicts of interest, researchers think of friendship and informal relationship highly. However, the consideration of friendship and informal relationship often causes conflicts of interest ironically.

- Co-researchers are not very active in opening research data and information or research capabilities. It is frequent that co-researchers are not true to the name (when a researcher lends his/her name).

It is notable that research ethics has been used as a means of personality attack against public figures recently in Korea. Such personality attacks are based on the research misconduct found in doctoral dissertations or academic work that were done more than 10 years ago when there was no such research ethics concept in Korea. Government guidelines of 2007 had a 5-year verification prescription with regard to academic work. Such provisions, however, were removed from the 2011 amendment. It is painful for such public figures to be attacked because of their research misconduct committed long before. On the other hand, the general public becomes disappointed and angry with such research misconduct, and consequently, general public comes to distrust leaders of society. And it is incidental that there arises an atmosphere where educators of research ethics are not welcomed.

\section{Problems and solutions at school}

This paper will now discuss about research ethics education at universities in Korea. According to the 2013 research ethics survey, 108 universities offer research ethics courses. However, only less than $20 \%$ offer regular courses while a half provide online courses. $44 \%$ provide students with research ethics education in the form of a onetime special lecture, and $24 \%$ take the form of consecutive special lectures through workshops. It is notable that professors and administrative staff are also given research 
ethics education albeit it takes the form of one-time special lecture or a series of special lectures under the name of 'workshop' (Lee 2014). This is partly because universities lack human resources specializing in research ethics education; in addition, they are not active in providing research ethics education.

\section{Embarrassing questions}

It is not easy to teach students research ethics that society balks at accepting due to disparity between conventions and values coupled with pre-mature conditions. In the course of classroom instruction, professors may receive embarrassing questions from students. Such questions, as shown below, based on conflicts deriving from disparity between, chiefly, traditional conventions and Western ethical standards:

- I understand the importance of internal whistle-blowing. But, is it ethical to accuse of my friend?

- In reality, internal whistleblowers are, in most cases, disadvantaged by his/her organizations. Do you want your students to be disadvantaged?

- In case of guiding professors or seniors make their dogmatic decisions, it is the convention of the research labs that students or juniors should not oppose their decisions. Ethical principles for joint research, therefore, are merely ideas up in the air for joint researchers.

Students point out that research misconduct cases are not dealt with reasonably mainly due to the deficient administrative system short of realizing research ethics.

- In Korea, institutional arrangements for conflict resolution of universities are very deficient. When graduate students, therefore, are entangled in conflicts with guiding professors, students will end up, in most cases, in serious trouble (they will leave school in the end.).

- As university administrative units are not reliable, it is desirable to report the case to external entities (e.g., government and mass media).

From an open innovation viewpoint, Korean academic community has some negative factors as follows:

- Cooperation doesn't work well due to the excessive competitions.

- Knowledge exchanges are very limited due to the closed mindset.

- Debates are intentionally avoided.

\section{Educational measures for research ethics}

To set research ethics in place more effectively under Korean circumstances, it would be needed to set educational goals and methods strategically depending on types of students. It will be responsible for the government to resolve the lack of research ethics educators. Then, what should be done in detail for this purpose? 
First, the level of research ethics education should be set for undergraduate and graduate students. It is advised that the scope of education should cover all of the afore-mentioned 13 norms because convergence research will become a commonplace in the future. For example, a non-biology major should know life ethics. It is necessary to set the minimal level of knowledge (e.g., principles, procedures, and standards) for each of the 13 norms as they have their own deep expertise respectively. The following five stages of education are proposed:

- Stage 1: Understanding general knowledge and importance of research ethics

- Stage 2: Understanding the principles of 13 norms, and capability to abide by the standards and procedures

- Stage 3: Understanding the principles, standards, and procedures of 13 norms, and ability to write lower-level norms as need (equivalent to the process of agreement on norms)

- Stage 4: Understanding the principles, standards, and procedures of 13 norms, and ability to resolve conflicts in the vicinity and to provide consulting service (Being able to introduce the norms of advanced countries)

- Stage 5: Ability to make a plan for the revision and development of the national system of ethical norms by applying new concepts (cases of the court of law) to research ethics

Government-led nurturing of expert educators is needed to make this education possible. It is advised that the government should provide financial support to universities so that they can open graduate programs to nurture experts with master's or doctoral degrees. Then, it will be appropriate for the nurtured personnel to work at universities as educators or specialized administrators. Without active strategies like this, research ethics in Korea will not have been established even in decades.

\section{Education for overcoming culture and values differences}

It would take time to overcome the differences in culture and values by educating people. In addition, classroom education at the university seems to have clear limitations. Education will take effect only with social changes leading to the establishment of the arrangements to resolve conflicts of interest, prohibition of retaliation against internal whistle-blowing, and reinvigoration of IRB functions.

What should be educated first is "to change the way of thinking rather than just delivering knowledge." For this,

- Educators should teach students to the extent that they can understand the principles of research ethics and comply with the standards and procedures. They should be educated to reach at least the second stage, and be given opportunities to discuss as many dilemma cases as possible. For this purposes, professors are supposed to introduce many cases of conflicts of interest to students to lead discussions with them.

- It is recommended to avoid unilateral delivery of knowledge through the Internet.

- There are merits with team teaching by experts of respective norms. Although team teaching is a method of teaching to promote expertise, it not a good method 
to promote understanding of general principles. In the case of team teaching, it will be advisable to allocate one educator to lead the whole classroom instruction.

Classroom instruction should be provided together with social education. Social education refers to social efforts to realize research ethics. Whatever "efforts" students see becomes an effective way to educate them.

- Universities should establish a consulting unit, a report receiving unit, and an investigation unit. Such units should be manned with experts. Considering the necessity of secretariat functions for IRB and IACUC, a big research ethics unit should be established.

- Researchers are recommended to have ethical discussions as frequently as possible in research rooms. In addition, as many practices as possible should be compiled and published in the form of manuals so that students can read them easily. Guiding professors who try to find solutions to ethical dilemmas will serve as a good model of social education for students.

- The government is required to establish legislation to facilitate these changes proactively and to provide financial incentives for universities. This legislative effort is the most important method for Korea to achieve qualitative growth in research ethics.

\section{Conclusion}

In this paper, it is discussed about how difficult to educate Western values in the East Asian culture context and is asserted education that 'provokes awakening' is needed than 'delivering knowledge' for the proper way of education. A big premise is required, however, to develop the methods of education as mentioned above. Do we want to introduce Western ethical system discarding traditional system of thinking? The answer is around our circumstances. As Korea adopted democracy and Western legal system, we cannot but criticizing traditional thinking system. There is no problem where the traditional values and those of Western's consensus, but where there are conflicts, a clear stance is inevitable. Nevertheless, depending on the situation, it is also needed to negotiate wisely to promote the positive aspects of collectivism and to suppress the negative aspects of it. For example, paternalism may be applied to helping neighbors in need while 'conflicts of interest' should be controlled to prohibit collective misconduct. Whistleblowers are now protected by laws, but relatively generous measures are also needed for those who couldn't whistle. It is notable that if someone had to be punished for his/her violation of the ethical norms in East Asia, the violater's institution, school and even the names of family members were disclosed to the public let alone the violater's individual penalty itself. Although there may be understandable aspects of ethical problems taking place due to the differences in culture and values, it should not be overlooked that there are chronic social evils that come down conventionally inside the group under the guise of traditional values.

Research Ethics forms the basis of the knowledge-based development. Research Ethics enables the open innovation and contributes significantly to the formation of sustainable economic culture (Francisco Javier Carrillo, 2015). This streamlines technology exchange, market strategies, public policy, and will form the basis of the overall social 
innovations (Philip Cooke, 2015). Thus research ethics goes beyond a simple academic objectives of the university level.

Research ethics should develop with social ethics. If the level of social ethics is not high enough, it is like building a house of cards to ask research ethics similar to the global standards of the research community. In this sense, universities should lead society to the right direction by playing the role of a fountain that pours clear water into society. The nation should have hope in universities exerting such efforts.

When students, who were educated at universities looking like a fountain, later contribute to the establishment of political ethics, social ethics, business ethics, military ethics, and ethics of public office desirably, democracy will become complete. The nation will, then, become a real advanced country.

Received: 23 October 2015 Accepted: 17 January 2016

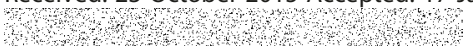

References

Francisco Javier Carrillo (2015). Knowledge-based development as a new economic culture. Journal of Open Innovation: Technology, Market, and Complexity Technology, Market, and Complexity. 1:15.

Hossain, M. (2013). Open innovation: so far and a way forward. World Journal of Science, Technology and Sustainable Development, 10(1), 30-41.

Husted, K., \& Michailova, S. (2010). Dual Allegiance and Knowledge Sharing in inter-Firm R\&D Collaborations. Organizational Dynamics, 39(1), 37-47.

Jeon, S., Kim, Y.-G., \& Koh, J. (2011). An integrative model for knowledge sharing in communities-of-practice. Journal of Knowledge Management, 15(2), 251-269.

JinHyo Joseph Yun (2015). How do we conquer the growth limits of capitalism? Schumpeterian Dynamics of Open Innovation. Journal of Open Innovation: Technology, Market, and Complexity. 1:17.

Kim, I. S. (1997). Imitation to Innovation. Cambridge, MA: Harvard Business School Press.

Lee, IJ (2013). Analysis on the Results of Research Ethics Activities and the Improvement Plan of Research Ethics in Korea, Korea Research Foundation.

Lee, IJ (2014). A study on Survey and Analysis of Research Ethics Activities in Korea, Korea Research Foundation. 158.

Nisbett, R. E. (2003). The Georaphy of Thought. New York: Free Press.

Philip Cooke (2015). Green governance and green clusters: regional \& national policies for the climate change challenge of Central \& Eastern Europe. Journal of Open Innovation: Technology, Market, and Complexity. 1:1.

Resnik, D (2010). What is Ethics in Research \& Why is It Important? http://www.niehs.nih.gov/research/resources/ bioethics/whatis.cfm.

Van de Vrande, V., De Jong, J. P. J., Vanhaverbeke, W., \& de Rochemont, M. (2009). Open innovation in SMEs: trends, motives and management challenges. Technovation, 29(6/7), 423-37.

Verena, N., \& Cornelius, H. (Eds.). (2014). R\&D Employee' intension to Exchange Knowledge within Open Innovation projects (pp. 1-26). Manchester: ISPIM Conference Proceedings.

Submit your manuscript to a SpringerOpen ${ }^{\circ}$ journal and benefit from:

- Convenient online submission

- Rigorous peer review

- Immediate publication on acceptance

- Open access: articles freely available online

- High visibility within the field

- Retaining the copyright to your article

Submit your next manuscript at $>$ springeropen.com 